\title{
Modeling Diffusive Flux of Non Point Source Pollutants in Lake Victoria: A Comparison Study of Fick's Law and the Fokker-Planck Law
}

\author{
N. Banadda ${ }^{\mathrm{a}, *}$, F. Ayaa $^{\mathrm{a}}$, I. Nhapi ${ }^{\mathrm{b}}$, U.G. Wali ${ }^{\mathrm{c}}$, R.J. Kimwaga ${ }^{\mathrm{d}}$ and D.A. Mashauri ${ }^{\mathrm{d}}$ \\ ${ }^{a}$ College of Agricultural and Environmental Sciences, Makerere University, P.O. Box 7062, Kampala, Uganda \\ ${ }^{b}$ Department of Civil Engineering, University of Zimbabwe, Box MP 167, Harare, Zimbabwe
}

${ }^{c}$ Faculty of Applied Sciences, National University of Rwanda, P.O. Box 117, Butare, Rwanda

${ }^{d}$ College of Engineering, University of Dar es Salaam, P. O. Box 35131, Dar es Salaam, Tanzania

\begin{abstract}
Mathematical models have the potential to conceptually quantify, link and simulate the interactive processes of nature. In this study 68 samples were collected at Gaba landing site in Uganda during a rainy season and were analyzed for nutrients, namely, Ammonia, Nitrite, Nitrate, and Phosphate. In addition, portable meters were used to measure Total Dissolved Solids (TDS) and Dissolved Oxygen (DO) instantaneously at point of sample collection. Within the lake, samples were taken at for horizontal transects of 10 metres $(\mathrm{m})$ interval over a distance of $50 \mathrm{~m}$ from the shore where surface runoff was released. At each $10 \mathrm{~m}$ sampling point, three samples were drawn at vertical distances of $0.5 \mathrm{~m}, 1.0 \mathrm{~m}$ and 1.5 $\mathrm{m}$ from water surface using a hand pump with graduated delivery pipe. This paper presents the results obtained from the application of two alternative expressions, fick's law and Fokker-Planck law to gain insight into the pollutants diffusive flux patterns within the lake. We conclude that in general the Fokker-Planck model should be given preference, in modelling Ammonia and Phosphate flux profiles while Fickian model should be deployed in modelling DO, TDS, Nitrites and Nitrates.
\end{abstract}

Keywords: Modeling and identification, control applications in environmental processes, water quality, nutrients, lake Victoria.

\section{INTRODUCTION}

Diffusion is one of the most fundamental phenomena in nature. Studies on diffusion processes in rivers and lakes are widely used by hydrodynamicists, hydrologists and environmental scientists involved in the study of water pollution problems. The time of travel of a pollutant in a river or lake, the rate at which the pollutant spreads, the decrease in peak concentration and the resulting concentration patterns of pollutant are the important variables that must be properly understood. Serious pollution may result if the capacity of the lake or steam to transport and disperse a contaminant is overestimated. Underestimation on the other hand may result in valuable resources not being optimally utilized, resulting in unnecessary expenditure on treatment facilities. The National Water and Sewerage Corporation charged with treating and supplying water to Kampala City dwellers are complaining of raising costs for treating Lake Victoria water [1]. A number of studies e.g., [2-6] have documented pollution as one of the major problems causing water quality deterioration. This is unfortunate due to the socio-economic importance of the lake. Lake Victoria is not only a source of food (fish), water, employment, transport, hydroelectric power, and recreation. In spite of the enormous attention that has been invested in tackling the pollution problem during the

*Address correspondence to this author at the College of Agricultural and Environmental Sciences, Makerere University, P.O. Box 7062, Kampala, Uganda; Tel \& Fax: +256-41-53.16.41; E-mail: banadda@agric.mak.ac.ug last three decades, it has persisted. In this study, Non- point source pollution (NPS) is mainly been the focus. Globally, 30 to $50 \%$ of the earth's surface is believed to be affected by NPS pollutants [7-9]. Agriculture remains as the single greatest contributor of these pollutants to soil and water resources [10]. The most common NPS pollutants include eroded sediments, fertilizers, pesticides, organic manures, salts, trace elements and sewage sludge. As pointed out by [11], the magnitude of NPS pollution is so complex and difficult to characterize that it defies proper evaluation with respect to its environmental impact. Nevertheless, NPS pollutants are recognized as the major contributors to surface and groundwater contamination worldwide [12]. Even within the highly industrialized, NPS pollutants impair far more rivers and lakes than point sources [13]. There have been many studies on dispersion and diffusion of pollutants in rivers and lakes. Probably the best-known study, usually quoted in texts on the subject, is the Fickian theory. It was developed for flow in pipes by $[14,15]$ and extended to channels by [16] and for natural streams by [17]. The proliferation of GIS-based models of NPS pollutants can be cause for optimism and caution [18]. On the positive side, visualization with GIS provides decision makers with a means of quickly digesting complex interrelated spatial patters of NPS distributions. On the negative side, unless these visualizations are accompanied with associated uncertainties, they can be falsely regarded as black and white representations of the truth, thereby creating the illusion of legitimacy. Against such a backdrop, this study will test the apparent popularity 

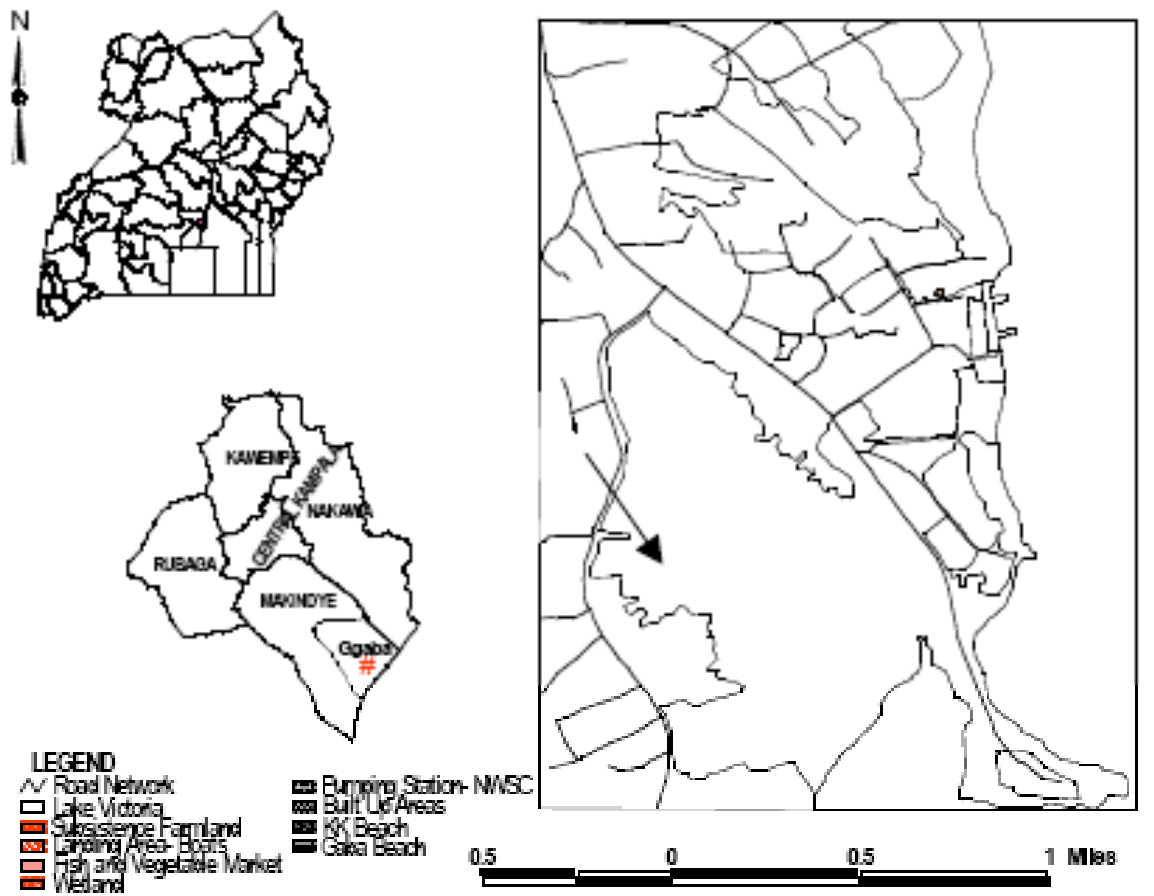

Fig. (1). Land Use Activities in Gaba, Kampala (Uganda).

of Fickian-type model by comparing it with the FokkerPlanck model. The global aim of this study is to compare two alternative expressions, fick's law and Fokker-Planck law to gain insight into the pollutants, namely, ammonia, nitrite, nitrate, phosphate, Dissolved Oxygen and Total Suspended Solids diffusive flux patterns within the lake.

\section{MATERIALS AND METHODS}

\subsection{Study Area}

The study was carried out at Gaba landing site located in Makindye division, Kampala (Uganda) as shown in Fig. (1). The choice of the study area was informed by it being a high activity area as far as NPS pollution is concerned.

\subsection{Sample Collection and Analysis}

In this study 68 samples were collected at Gaba landing site in Uganda during a rainy season. To ensure that samples were always taken from the same spot within the lake, mapping of the sampling points were done using GPS on a boat ride. The sampling coordinates were stored in a GPS and later traced during subsequent sampling. The mapping was done after rain event in order to locate the path/areas these runoff normally follow when released into the Lake. Samples were stored in a cooler and transported within less than two hours for lab analysis which include nutrients (Ammonia, Nitrite, Nitrate, and Phosphate). Total Dissolved Solids (TDS) and Dissolved Oxygen (DO) were measured instantaneously at point of sample collection. Meanwhile within the lake samples were taken at for horizontal transects of $10 \mathrm{~m}$ interval over a distance of $50 \mathrm{~m}$ starting from the shore where surface runoff was released. For the same sampling points within the lake, samples were drawn at vertical distances of $0.5 \mathrm{~m}, 1.0 \mathrm{~m}$ and $1.5 \mathrm{~m}$ from water surface using a hand pump with graduated delivery pipe so as to take samples at the required vertical depth.

\subsection{Model Selection and Modeling Approach}

The modeling of (particle) diffusion is normally based on two assumptions. The first is the conservation of the number of particles:

$$
\frac{\partial n(x, t)}{\partial t}=\frac{\partial \Gamma(x, t)}{\partial x}
$$

where $\mathrm{n}(x, t)$ is the particle density and $\Gamma(x, t)$ is the particle flux through the point $x$. The second assumption is a relation between the flux, $\Gamma$, and the density. If one has a full theory for the particle motion (kinetic or microscopic), one may derive $\Gamma$ directly from the particle dynamics which is Fick's Law as shown in Equation (2). However, if a theory is lacking or incomplete, it is customary to apply a phenomenological relation.

$\Gamma(x, t)=-D(x) \frac{\partial n(x, t)}{d x}$

where $D$ is the diffusion coefficient. For Fick law, we assumed a constant D of $10^{-4}$ [19]. To reconcile the experimentally observed fluxes with theory, often ad hoc convective terms (i.e., $V(x) \cdot n$ ) or drifts are added to the particle flux, which in many cases are difficult to justify physically [20]. However, the need for these drifts and their physical interpretation can be perfectly justified from a theoretical standpoint without such additional terms. Indeed, it has long been known (although widely ignored) that the diffusion is subject to a spatial inhomogeneity satisfies the so-called FokkerPlanck diffusivity law as depicted in Equation (3).

$$
\Gamma(x, t)=-\frac{\partial[D(x) n(x, t)]}{d x}
$$




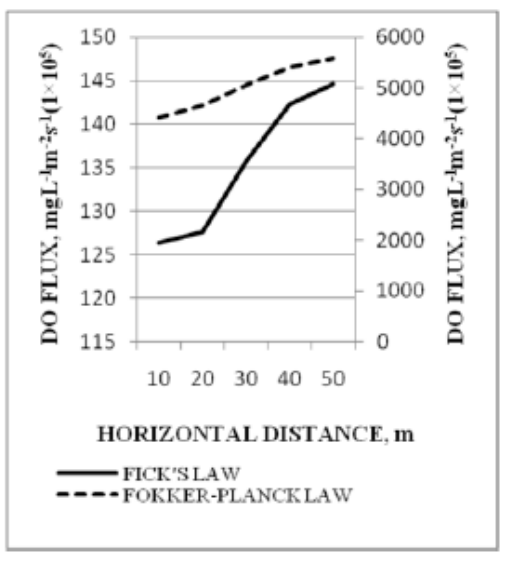

(a)

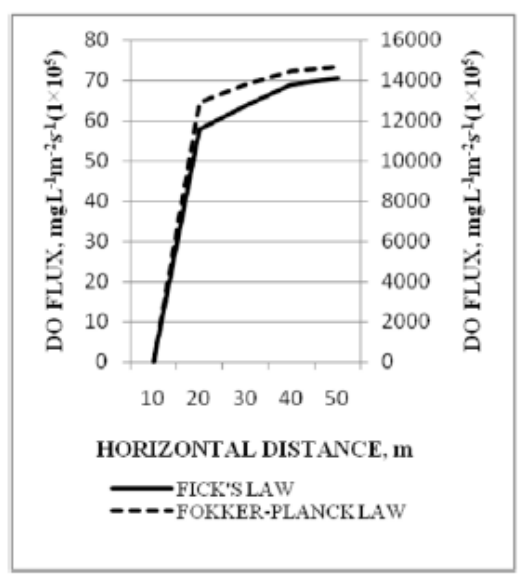

(b)

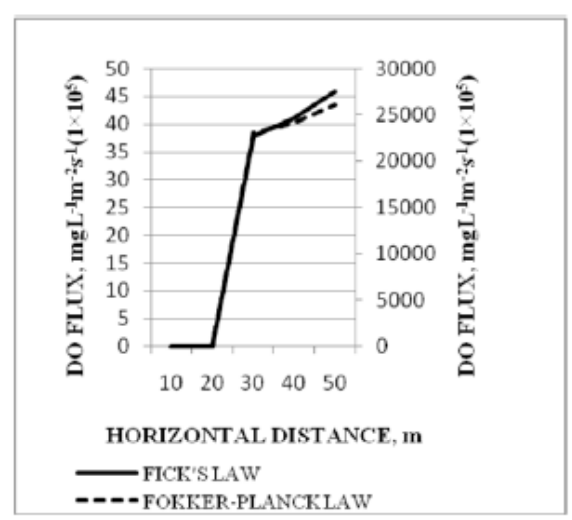

(c)

Fig. (2). Dissolved Oxygen flux profiles at a depth of (a) $0.5 \mathrm{~m}$ (b) $1.0 \mathrm{~m}$ and (c) $1.5 \mathrm{~m}$.

Where $\mathrm{D}=0.0142 \mathrm{E}^{1.49}$ with $\mathrm{E}$ being the depth $(\mathrm{m})$ according to [21]. Diffusion is a macroscopic process that reflects underlying random motion at a microscopic level. The main result of this formalism is the generalized master equation, which provides a probabilistic description of the microscopic motion. In the case of Markovian particle motion (in which each random step of every particle is taken from a probability distribution $p$ without any influence from the past history of the system) as shown in Equation (4).

$$
\frac{\partial n(x, t)}{d t}=\int \mathrm{d} x^{\prime} p\left(x-x^{\prime} ; x^{\prime}, t\right) \frac{n\left(x^{\prime}, t\right)}{\tau_{D}(x \prime)}-\frac{n(x, t)}{\tau_{D}(x)}
$$

In spite of the apparent complexity of this integrodifferential equation, its interpretation is easy. It states that the rate of change of particles at location $x$ and time $t$ is given by adding the new particles that arrive and subtracting those that leave, per time unit. Those arriving move in from another location $x$ ' by a process with a probability given by $p\left(x-x^{\prime}, x^{\prime}, t\right)$. The time scale governing the motion is given by $\tau_{D}\left(x^{\prime}\right)$.

\section{RESULTS AND DISCUSSIONS}

\subsection{Dissolved Oxygen (DO) Flux Profiles}

Fig. (2) depicts the dissolved Oxygen flux profiles modelled by Fick law and Fokker-Planck law. Generally, Fick's model shows a decreasing trend in DO flux values as depth increases from 0.5 metres to 1.5 metres. On the other hand, Fokker-Planck model shows an increasing trend in DO flux over a similar depth. Measured DO data showed a decreasing DO trend with increasing depth $[22,23]$. At a depth of $0.5 \mathrm{~m}$, higher DO flux values were obtained at the shores and subsequently decreased with increasing horizontal distance. This is due to inflow of polluted runoff. A comparison of the two models shows that Fickian model is closer to reality as compared to Fokker- Planck model. At a horizontal distance of approximately $25 \mathrm{~m}$, depth of $1.0 \mathrm{~m}$ and $1.5 \mathrm{~m}$, a marked increase in DO flux is observed.

\subsection{Total Dissolved Solids (TDS) Flux Profiles}

Fig. (3) depicts the Total Dissolved Solids (TDS) dissolved Oxygen flux profiles modelled by Fick law and Fokker-Planck law. It can be noted that Fickian model shows a decrease in TDS flux values with increase in depth, although similar values were obtained at depth of $1 \mathrm{~m}$ and $1.5 \mathrm{~m}$. Interestingly, Fokker-Planck model show increasing TDS flux values with increase in depth. Field TDS measurements showed a decreasing pattern in TDS values with increase in depth. At the shore, higher TDS flux is noted and decrease as one moves horizontally into the lake. A comparison of the two models shows that Fickian model is closer to reality as compared to Fokker- Planck model. 


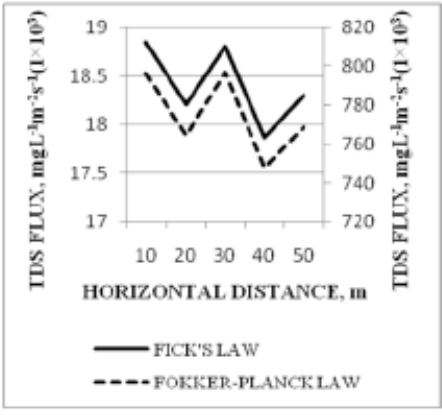

(a)

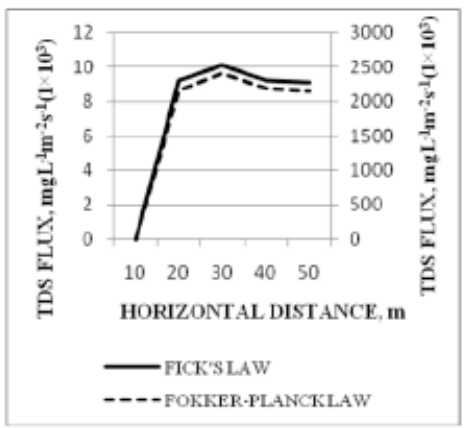

(b)

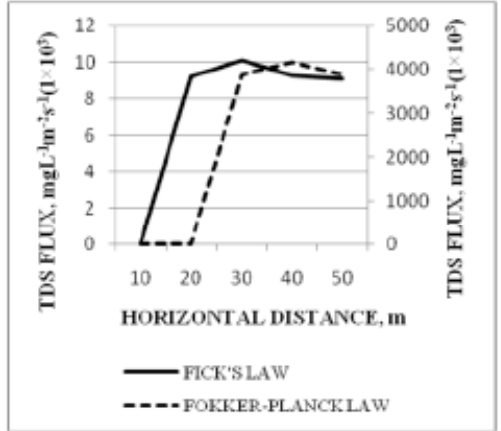

(c)

Fig. (3). Total Dissolved Solids (TDS) Flux Profiles at a depth of (a) $0.5 \mathrm{~m}$ (b) $1.0 \mathrm{~m}$ and (c) $1.5 \mathrm{~m}$.

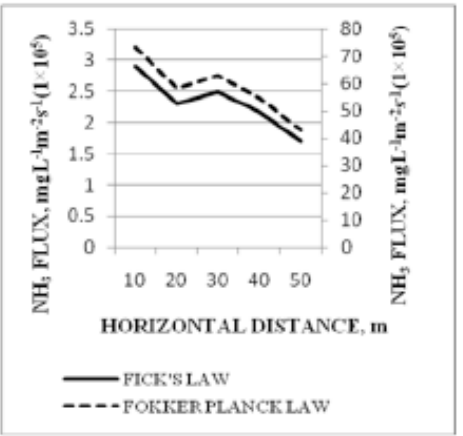

(a)

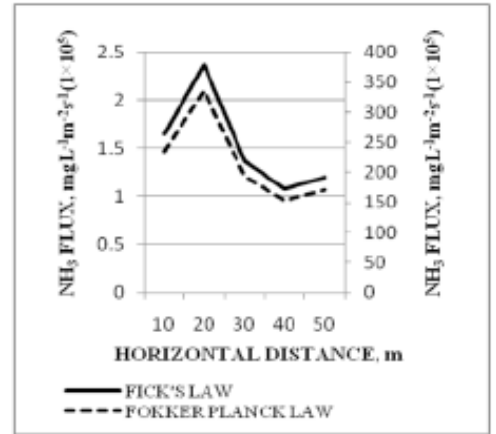

(b)

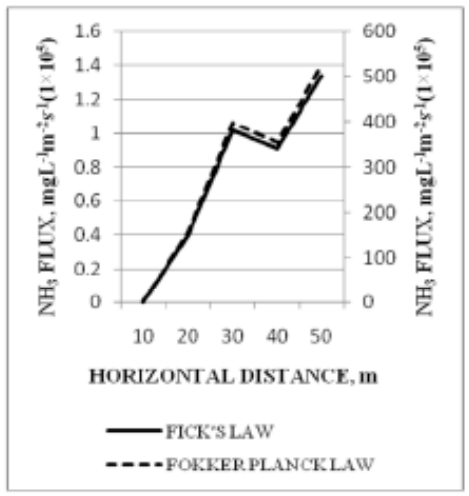

(c)

Fig. (4). Ammonia Flux Profiles at a depth of (a) $0.5 \mathrm{~m}$ (b) $1.0 \mathrm{~m}$ and (c) $1.5 \mathrm{~m}$.

\subsection{Ammonia Flux Profiles}

Fig. (4) shows the Ammonia flux profiles modelled by Fick law and Fokker-Planck law. Fickian model shows higher Ammonia flux values at the shore and a depth of 0.5 $\mathrm{m}$. At the shore but a depth of $1.5 \mathrm{~m}$, zero flux is noted. This means that there is no concentration gradient as runoff enters the lake. Fickian model Ammonia Flux values stagnant at approximately $1.3 \mathrm{mgL}^{-1} \mathrm{~m}^{-2} \mathrm{~s}^{-1}$ with increased depth and 


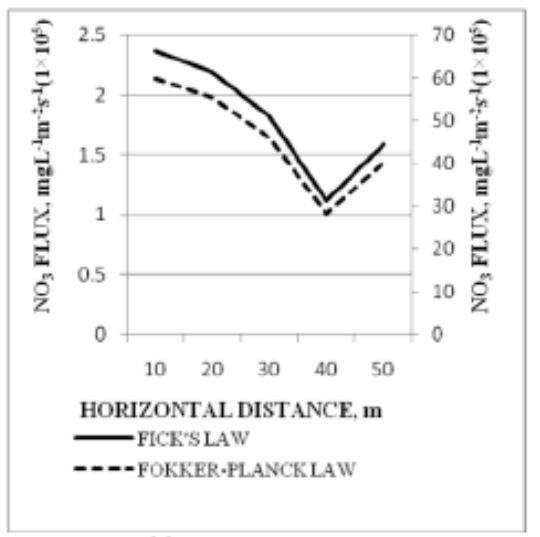

(a)

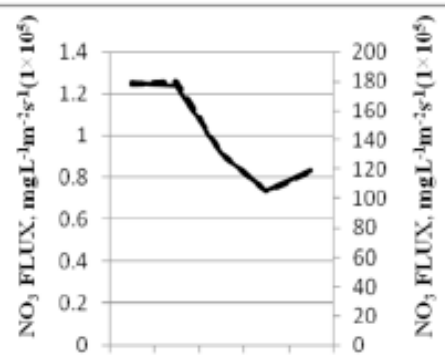

$10 \quad 20 \quad 30 \quad 40 \quad 50$

HORIZONTAL DISTANCE, $m$

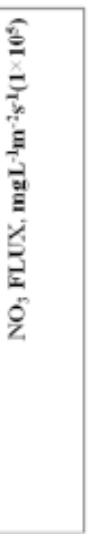

(b)

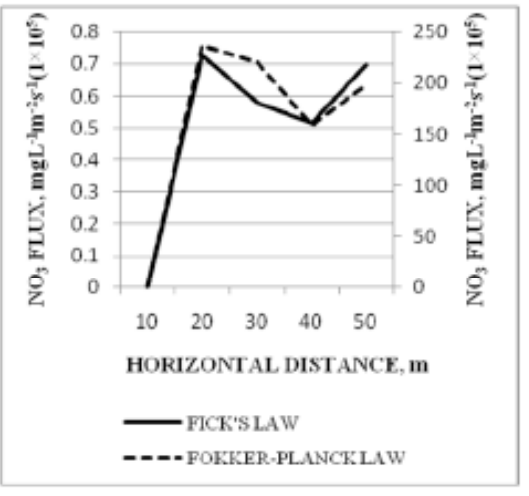

(c)

Fig. (5). Nitrates Flux Profiles at a depth of (a) $0.5 \mathrm{~m}$ (b) $1.0 \mathrm{~m}$ and (c) $1.5 \mathrm{~m}$.

horizontal distance. On the other hand, Fokker-Planck model values increase with increasing depth and horizontal distance. Fickian model in Fig. (1) seemed to agree with literature e.g., [23] as far as DO is concerned. Therefore, anoxia seems a reality. Anoxia in the bottom waters is produced through lack of resupply of oxygen from the surface and bacteria consuming the oxygen through respiration. Bacterial breakdown of dead plant and animal material produces ammonium as a by-product. Due to limited mixing, ammonium concentrations increase and become quite high in the bottom waters. In this regard, Fokker-Planck model seems closer to measured Ammonia values.

\subsection{Nitrites and Nitrates Flux Profile}

In Fig. (4 and 5), it can be noted that Nitrite and Nitrate fluxes are higher at the shore and depth of $0.5 \mathrm{~m}$. This is due to surface runoff entering the lake. Generally, Fickian model Nitrite and Nitrate values decreased with increased depth and horizontal distance. However, at all the three depths considered in this study, Nitrate flux was higher than Nitrite flux. Both models reported this trend and increase in Nitrate flux as compared to Nitrite. This concurs with what is reported in literature as [8] in their works noted that Nitrite concentrates showed an inverse relationship to Nitrate concentrates. Fokker-Plnack model indicate that as Nitrate flux value increase so do Nitrites. Fickian model indicate that as Nitrate flux values increase, Nitrite flux values decrease. In the surface water, DO concentration is high enough to oxidize Nitrites to Nitrates. Therefore, under these circumstances, Fickian model is closer to reality.

\subsection{Phosphates Flux Profile}

In Fig. (6), Fokker-Planck model shows that the phosphates flux increase with horizontally at depth of $1 \mathrm{~m}$ and 1.5 $\mathrm{m}$. On the hand, the Fickian model depicts an increase in phosphate flux with increase in horizontal distance at depth of $1 \mathrm{~m}$ and $1.5 \mathrm{~m}$. However, the Fickian model shows that phosphate flux decrease with increase in depth while the Fokker-Planck model depicts an inverse trend. Literature supports the trend observed in the Fokker-Planck model. A study carried out by [23] shows that phosphate concentrations are high with increasing depth.

\section{CONCLUSIONS \& PERSPECTIVES}

This work presents the results of application of two alternative expressions, fick's law and Fokker-Planck law to gain insight into the pollutants diffusive flux patterns within Lake Victoria. Mathematical modelling appears to be a powerful tool to predict pollution diffusive flux in the case study presented. ON one hand, Fickian model showed a satisfactory agreement with measured data in predicting DO, TDS, Nitrites and Nitrates flux profiles. On the other hand, FokkerPlanck model should be given preference in modeling Phopshates and Ammonia flux profiles. However, the Fickian model is more popular and largely deployed than the Fokker-Planck model. Future works should focus on dispersion studies, i.e., variations of NPS pollutant concentrations with time and space. In general, it can be concluded that: 


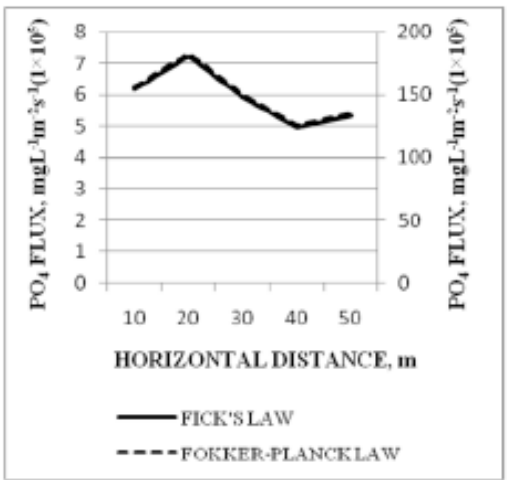

(a)

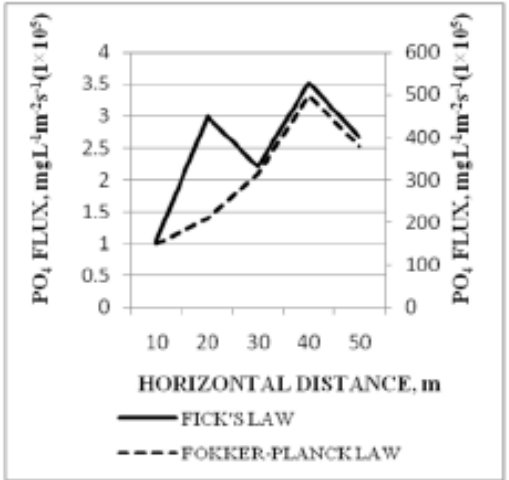

(b)

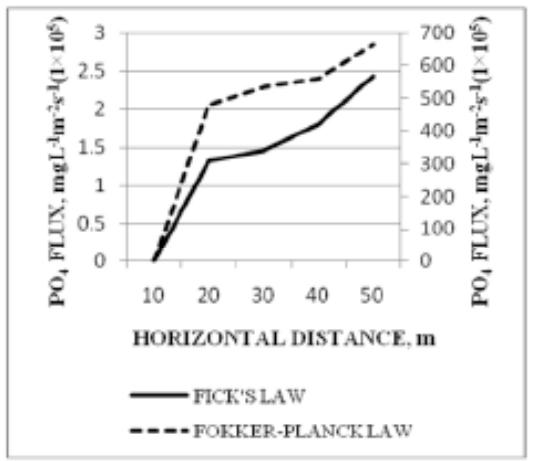

(c)

Fig. (6). Phosphates Flux Profiles at a depth of (a) $0.5 \mathrm{~m}$ (b) $1.0 \mathrm{~m}$ and (c) $1.5 \mathrm{~m}$.

- Increase in land use \& urbanization in shore settlements of Lake Victoria has increased nutrient and dissolved solids concentration in surface runoff resulting into deterioration in their quality

- Surface runoff discharged into Lake Victoria causes an elevation in nutrient and physico-chemical parameter concentrations

- Availability of fish especially in environs close to shore settlements is diminished due to high water pollution loads.

\section{ACKNOWLEDGEMENTS}

Acknowledgement is made to SIDA/SAREC through the Inter University Council for Eastern Africa that funded this work under the Lake Victoria Research (VICRES) programme.

\section{REFERENCES}

[1] E.N. Banadda, F. Kansiime, M. Kigobe, M. Kizza and I. Nhapi, "Landuse-based non-point source pollution: a threat to Murchison bay water quality in Uganda", Water quality II supplement 1, pp. 93-104, 2009

[2] I.N. Makundi, "A study of heavy metal pollution in Lake Victoria sediments by Energy Dispersive X-Ray Fluorescence", Environmental Science and Health Part A - Toxic/Hazardous Substances and Environmental Engineering, vol. 36, no. 6, pp. 909-921, 2001.

[3] L.M. Campbell, J.S. Balirwa, D.G. Dixon and R.E. Hecky, "Biomagnification of mercury in fish from Thruston Bay, Napoleon Gulf, Lake Victoria”, East African Journal of Aquatic Science, vol. 29, no.1, pp. 91-96, 2004.

[4] P. Kyomuhendo, "A bioeconomic model for Uganda's Lake Victoria Nile Perch fishery", M.S. thesis, Universitetet Tromso, Norway, 2002.
[5] P. Larsson, "Lake Victoria and Kampala - history of man and water", Technical report, Kampala, Uganda, 2002.

[6] S.V. Matagi, "Some issues of environmental concern in Kampala, the capital city of Uganda", Environmental Monitoring and Assessment, vol. 77, pp. 121-138, 2002.

[7] D. Muhirwa D. I. Nhapi, U. G. Wali, N. Banadda, J.J. Kashaigili and R. Kimwaga, "Characterization of wastewater from an abattoir in rwanda and the impact on downstream water quality", International Journal of Ecology and Development, vol. 16, no. 10, pp. 3046, 2010.

[8] D. Pimental, World Soil Erosion and Conservation, Cambridge University Press, Cambridge, England, 1993.

[9] T. Nkurunziza, J.B. Nduwayezu, E.N. Banadda and I. Nhapi, “The effect of turbidity levels and Moringa Oleifera concentration on the effectiveness of coagulation in water treatment", Water Science and Technology, vol. 59, no. 8, pp. $1551-1558,2009$.

[10] F.J. Humenik, M.D. Smolen and S.A. Dressing, "Pollution from nonpoint sources: Where we are and where we should go", Environmental Science and Technology, vol. 21, no.8, pp. 737-742, 1987.

[11] A.M. Duda, "Addressing Non-point sources of water pollution must become an international priority", Water Science and Technology, vol. 28, no. 3-5, pp. 1-11, 1993.

[12] A.M. Duda and M. Nawar, "Implementing the World Bank's water resources management policy: A priority on toxic substances from nonpoint sources", Water Science and Technology, vol. 33, no.4-5, pp. 45-51, 1996.

[13] U.S. Environmental Protection Agency, "National water quality inventory", U. S. Government, Printing Office, 1994.

[14] G.I. Taylor, "Dispersion of soluble matter in solvent flowing through a tube", Processing Research Series A, vol. 219, pp. 186203, 1954.

[15] J.W. Elder, "The dispersion of marked fluid in turbulent shear flow", Journal of Fluid Mechanics, vol. 5, pp. 544-560, 1959.

[16] H.B. Fischer, "A note on the one-dimensional dispersion model", Air and Water pollution International journal, vol. 10, pp. 443-453, 1966.

[17] D.L. Corwin and R.J. Wagenet, "Applications of GIS to the modeling of non-point source pollutants in the Vadose zone: A confer- 
ence overview", Journal of Environmental Quality, vol. 25, no. 3, pp. 403-411, 1996.

[18] J.L. Schnoor, Environmental Modeling: Fate and Transport of Pollutants in Water, Air, and Soil. Wiley-Interscience, 1996.

[19] B.P. Van Milligen, P.D. Bons, B.A. Carreras and R. Sanchez, "On the applicability of Fick's law to diffusion in inhomogeneous systems", European Journal of Physics, vol. 26, pp. 913-925, 2005.

[20] H.E. Jobson and W.W. Sayre, "Predicting concentration profiles in open channel", Journal of Hydraulic Division ASCE, vol. 96, no. 10, pp. 1983-1995, 1970.
[21] N. Banadda, I. Nhapi and U. G. Wali, "Characterization of non point source pollutants and their control in Lake Victoria: A case study of Gaba Landing site Uganda", African Journal of Environment Science and Technology, vol.5, no. 2, pp. 73 -79, 2011.

[22] Y. Yamaoka, T. Tanimoto and T. Shiozawa, "Vertical distributions of Nitrogen, Phosphorus and Iron in Beppu Bay", Journal of the Oceanographical Society of Japan, vol. 39, pp. 301-304, 1983.

[23] F.C. Ezeonu and A. N. C. Okaka, "Seasonal profile of nitrate and nitrite in potable water sources in onitsha, Nigeria", Environmental Toxicology and Water Quality, vol. 11, pp. 99-103, 1998.

Received: December 06, 2010

(C) Banadda et al.; Licensee Bentham Open.

This is an open access article licensed under the terms of the Creative Commons Attribution Non-Commercial License (http://creativecommons.org/licenses/by-nc/3.0/g) which permits unrestricted, non-commercial use, distribution and reproduction in any medium, provided the work is properly cited. 